of deletions in the human factor IX gene. Am J Hum Genet 1994; 54: 201-13.

4 Wolff DJ, Gustashaw KM, Zurcher V et al. Deletions in Xq26.3-q27.3 including FMR1 result in a severe phenotype in a male and variable phenotypes in females depending upon the $\mathrm{X}$ inactivation pattern. Hum Genet 1997; 100: 256-61.

5 Anson DS, Blake DJ, Winship PR, Birnbaum D, Brownlee GG. Nullisomic deletion of the mcf.2 transforming gene in two haemophilia B patients. EMBO J 1988; 7: 2795-9.
6 Laumonnier F, Ronce N, Hamel BC et al. Transcription factor SOX3 is involved in $\mathrm{X}$-linked mental retardation with growth hormone deficiency. Am J Hum Genet 2002; 71: 1450-5.

7 Siggs OM, Arnold CN, Huber $\mathrm{C}$ et al. The P4-type ATPase ATP11C is essential for B lymphopoiesis in adult bone marrow. Nature Immunol 2011; 12: 434-40.

8 Yabas M, Teh CE, Frankenreiter $\mathrm{S}$ et al. ATP11C is critical for the internalization of phosphatidylserine and differentiation of $\mathrm{B}$ lymphocytes. Nature Immunol 2011; 12: 441-9.

9 Wu QF, Yang L, Li S et al. Fibroblast growth factor 13 is a microtubule-stabilizing protein regulating neuronal polarization and migration. Cell 2012; 149: 1549-64.

10 Duzkale H, Schweighofer CD, Coombes KR et al. LDOC1 mRNA is differentially expressed in chronic lymphocytic leukemia and predicts overall survival in untreated patients. Blood 2011; 117: 4076-84.

\title{
Management of intracranial surgery for refractory epilepsy in severe factor VII deficiency: choosing the optimal dosing regimen
}

\author{
M. RAJPURKAR, * M. CALlAGHAN, * M. J. FREY,, K. SET, $\dagger$ H. CHUGANI $\dagger$ and S. SOOD $\$$ \\ *Division of Hematology Oncology, Carman and Ann Adams Department of Pediatrics, Children's Hospital of Michigan, \\ Wayne State University, Detroit, MI, USA; †Division of Neurology, Carman and Ann Adams Department of Pediatrics, \\ Children's Hospital of Michigan, Wayne State University, Detroit, MI, USA; and \$Department of Neurosurgery Children's \\ Hospital of Michigan, Detroit, MI, USA
}

Inherited factor VII deficiency (FVIID) is the most common 'rare' bleeding disorder and is characterized by a variable bleeding tendency. A subgroup of patients with FVIID present with a severe clinical bleeding phenotype characterized by spontaneous bleeding in early infancy [1]. Surgery in such patients carries a risk of bleeding and the optimal treatment regimen for major surgeries has still not been defined. Continuous infusion of rFVIIa (CI-rFVIIa) has been used most commonly during orthopaedic surgery with good outcomes; however, experience with CI-rFVIIa is limited, with very few data on comparisons between bolus and continuous infusion regimens [2].

We present a patient with severe FVIID (FVII activity $<1 \mathrm{IU} \mathrm{mL}^{-1}$ ) with intractable atonic (drop) seizures attributed to a spontaneous intracranial haemorrhage $(\mathrm{ICH})$ in the neonatal period who underwent a total corpus callosotomy for control of seizures. Preoperatively, we administered rFVIIa in three dosing regimens so as to enable us to choose the optimal regimen for use during and after his planned major neurosurgi-

Correspondence: Madhvi Rajpurkar, MD, Division of Pediatric Hematology Oncology, Carman and Ann Adams Department of Pediatrics, Children's Hospital of Michigan, Wayne State University, Detroit, MI 48201, USA.

Tel.: 1313745 5515; fax: 1313745 5237;

e-mail: mrajpurk@med.wayne.edu

Accepted after revision 3 February 2014

DOI: 10.1111/hae.12397 cal procedure. Preoperatively, we monitored tissue factor thromboelastographic (TF-TEG) parameters, prothrombin time (PT) and FVII activity after the three rFVIIa doses. Eventually, we chose one dosing regimen for use during surgery and the patient successfully underwent the surgery with no bleeding complications and had an excellent outcome.

The patient is an 8-year-old male of Middle Eastern origin who was diagnosed with severe FVIID in the neonatal period. He developed a right-hemispheric $\mathrm{ICH}$ at 24 days of age. At approximately seven and a half years of age, he developed recurrent seizures consisting of sudden drops that were precipitated by unanticipated auditory stimuli. These gradually increased in frequency from 2 per day to 20 per day and the seizures were resistant to different antiepileptic medications. Due to the seizures, the patient sustained multiple falls and developed recurrent musculo-skeletal bleeding episodes. Due to the risk for secondary haemorrhage as well as the negative impact on his quality of life, surgical options were explored. Vagal nerve stimulation (VNS), corpus callosotomy or a right hemispherectomy was considered for controlling his seizures. The major disadvantage of hemispherectomy was potential catastrophic bleeding while that of VNS was that rarely does this abolish all seizure episodes. A more conservative surgery (i.e. total corpus callosotomy) was considered to be the most reasonable option, offering an $80 \%$ chance of total seizure control in atonic (drop) seizures. 
Preoperatively, the patient electively received three different dosing treatments with rFVIIa (NovoSeven ${ }^{\circledR}$ RT; Novo Nordisk A/S, Bagsvaerd, Denmark) on three separate days: (i) $1 \mathrm{mg}$ bolus $\left(27 \mu \mathrm{g} \mathrm{kg}^{-1}\right.$, low-dose bolus, LDB-rFVIIa), (ii) $2 \mathrm{mg}$ bolus ( $54 \mu \mathrm{g} \mathrm{kg}^{-1}$, highdose bolus, HDB-rFVIIa) and (iii) continuous infusion rFVIIa (CI-rFVIIa). Continuous infusion dose was administered as follows. The patient received a bolus of $0.3 \mathrm{mg}\left(8 \mu \mathrm{g} \mathrm{kg}^{-1}\right)$ followed by a continuous infusion of $1.7 \mathrm{mg}$ over the next $5 \mathrm{~h}\left(\sim 9 \mu \mathrm{g} \mathrm{kg}^{-1} \mathrm{~h}^{-1}\right)$. Due to the small volume of reconstituted rFVIIa, $1.7 \mathrm{mg}$ of rFVIIa was diluted in $15 \mathrm{~mL}$ of normal saline and infused at $3 \mathrm{~mL} \mathrm{~h}^{-1}$.

As he was on secondary prophylaxis with rFVIIa, the prophylactic dose was held on the day of testing to allow for a washout interval of at least $24 \mathrm{~h}$. The rFVIIa was infused via a tunnelled central venous catheter and all samples were collected via a peripheral venous draw. Samples were collected for PT, FVII activity and TF-TEG at baseline (pre-rFVIIa) and at 1 , 2, 4 and $6 \mathrm{~h}$ after the bolus doses. For CI-rFVIIa, samples were drawn at baseline and at $15 \mathrm{~min}$ and at 1 , 2 and 4 h. Factor VII activity was tested in citrated plasma $(3.2 \%)$ using a one-stage mechanical clotting assay on the STA-R Evolution (Diagnostica Stago, Parsippany, NJ, USA). The assay utilized a calcium thromboplastin from rabbit cerebral tissues (Neoplastine CI; Diagnostica Stago) with human factor VIIdeficient plasma (George King Bio-Medical, Inc. Overland Park, KS, USA) to measure the clotting time vs. the standard plasma (STA Unicalibrator; Diagnostica Stago). TF-TEG was performed as per a published method [3]. The results are documented in Table 1 and Fig. 1.

As the PT, FVII and TEG parameters were most stable after CI- rFVIIa, a decision was made to use this regimen for surgery. The patient received CI-rFVIIa as described above (the bolus dose was given just prior to surgery followed by continuous infusion during and after surgery). The patient underwent the surgery with an estimated blood loss of $50 \mathrm{~mL}$. We were able to decrease his CI-rFVIIa further on postoperative days $2\left(7 \mu \mathrm{g} \mathrm{k}^{-1} \mathrm{~h}^{-1}\right)$ and $3\left(4.5 \mu \mathrm{g} \mathrm{k}^{-1} \mathrm{~h}^{-1}\right)$ as his PT, FVII activity and TFTEG were in the acceptable range with no bleeding (Table 2). The continuous infusion was stopped on postoperative day 8 and the patient was discharged home on prophylactic rFVIIa regimen (home regimen). The patient has been seizure free for more than 9 months after surgery and continues on secondary rFVIIa prophylaxis ( 2 mg rFVIIa every other day) for prevention of recurrent ICH.

Congenital severe FVII deficiency (FVIID) is a rare bleeding disorder characterized by broad clinical heterogeneity. Replacement of FVII by giving plasma-derived FVII, rFVIIa, fresh frozen plasma or prothrombin complexes remains the treatment of

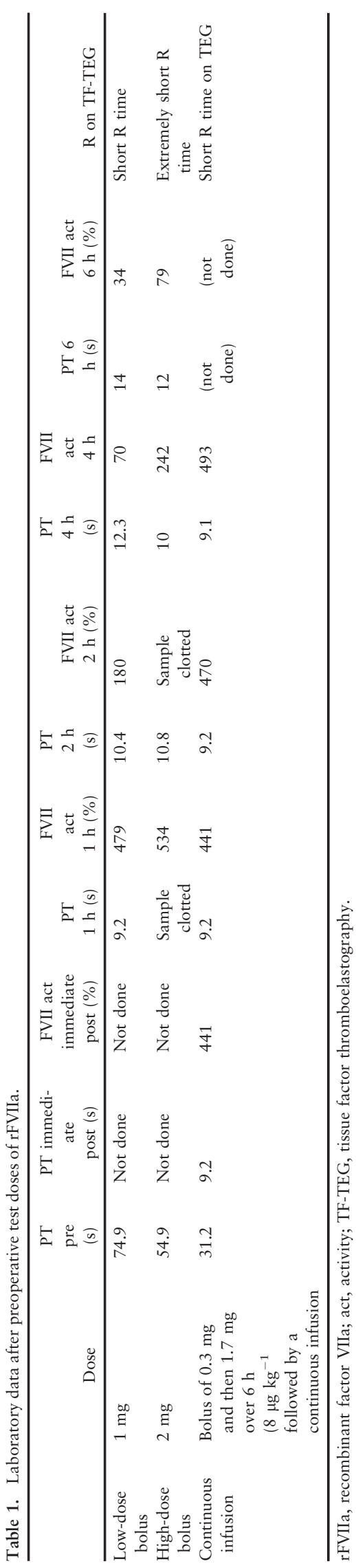



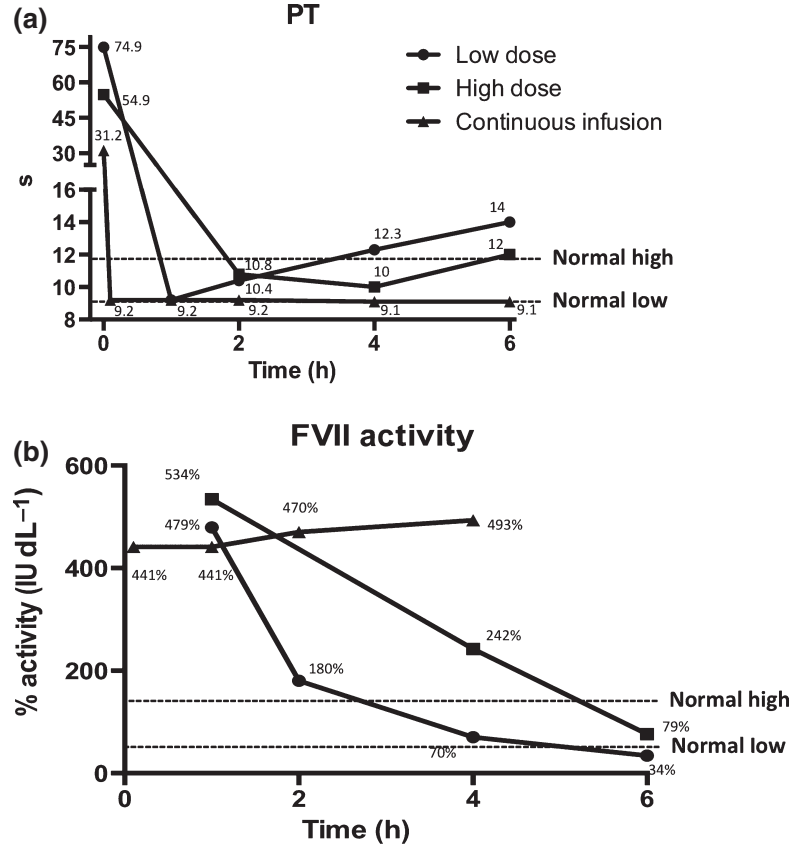

Fig. 1. Sequential changes in prothrombin time (PT) and factor VII activity (refer Table 1 for actual numbers).

choice for patients with bleeding and for those undergoing surgery [4]. Bleeding from surgical procedures has been reported in one-third of the patients with FVIID and risk of bleeding varies with the type of surgery, tissue or organ involvement and the type of anaesthesia [5]. Previous reports of bolus doses ranging from 15 to $90 \mu \mathrm{g} \mathrm{kg}^{-1}$ have been used in patients at an interval of 4-6 h [6]. Such regimens, however, lead to wide fluctuations in the FVIIa activity with supratherapeutic levels after the bolus doses and sub-therapeutic levels by hour 4 [7]. Factor VII replacement after surgery has also been associated with the development of an inhibitor and thrombotic complications $[4,8]$.

Recently, an analysis from the Seven Treatment Evaluation Registry for surgical procedures was published in which surgeries were classified as either major (open abdominal, orthopaedic, cardiovascular or neurosurgery) or minor [5]. Of the 41 elective surgeries in
34 patients, only three patients received continuous infusions. There were seven patients with FVII level of $<1 \%$ but none had central nervous system bleeding and presumably did not undergo a neurosurgical procedure. The minimally effective dose was deemed to be $13 \mu \mathrm{g} \mathrm{kg}^{-1}$ body weight with two additional doses. This supports the concept proposed by other researchers that in FVIID patients, a lower dose of FVIIa may be needed for achieving haemostasis [9]. Given the wide fluctuations in FVII levels obtained with bolus dosing and the risk of inhibitor formation or thrombosis with such dosing regimens, we felt that low-dose CI rFVII was the optimal regimen for our patient.

There is no consensus regarding the dose or rate of continuous infusion of rFVIIa. Schulman et al. reported bolus doses in their study ranging from 4 to $66 \mu \mathrm{g} \mathrm{kg}^{-1}$ followed by continuous infusion with variable doses [6]. A publication by Tran et al. reported the effective use of CI-rFVIIa in 13 major surgeries out of 25 surgical procedures, all of which were non-central nervous system surgeries [2]. They used a bolus dose of $8.5 \mu \mathrm{g} \mathrm{kg}^{-1}$ followed by a rate of $0.9 \mu \mathrm{g} \mathrm{kg}^{-1} \mathrm{~h}^{-1}$ along with tranexamic acid and reported a significant reduction in use of medication usage and cost.

In our patient, we were able to compare three dosing regimens prior to a major elective neurosurgical procedure. After LD-bolus dose, the PT was found to be prolonged after $4 \mathrm{~h}$. Conversely, several of the samples after HDB-rFVIIa were clotted, suggesting extremely high levels of FVII. An analysis of laboratory measurements (PT, FVII levels and TEG), revealed low dose continuous infusion to be superior to bolus doses. This regimen was subsequently chosen for the surgery. Due to a possible additional risk of thrombosis with tranexamic acid, we chose to eliminate the use of tranexamic acid (as described previously by Tran et al.) but chose to give a higher dose of continuous infusion of rFVIIa [2]. Once surgical haemostasis was achieved, we were able to rapidly wean the CI-rFVIIa dose on days 2 and 3 postoperatively with normalization of haemostatic parameters.

To our knowledge, this is the first study that has compared three different dosing regimens prior to an elective major neurosurgical procedure. We found that

Table 2. Intra- and postoperative management of continuous infusion of rFVIIa.

\begin{tabular}{|c|c|c|c|c|c|}
\hline & Preoperative & Intraoperative & Postoperative day 1 & Postoperative day 2 & Postoperative days 3-7 \\
\hline Bolus dose & $0.3 \mathrm{mg}\left(8 \mu \mathrm{g} \mathrm{kg}^{-1}\right)$ & NA & NA & NA & NA \\
\hline $\begin{array}{l}\text { Continuous } \\
\text { infusion }\left(\mu \mathrm{g} \mathrm{kg}^{-1}\right)\end{array}$ & $1.7 \mathrm{mg} / 5 \mathrm{~h}\left(9 \mu \mathrm{g} \mathrm{kg}^{-1} \mathrm{~h}^{-1}\right)$ & $\begin{array}{l}2 \mathrm{mg} / 6 \mathrm{~h} \\
\left(9 \mu \mathrm{gg} \mathrm{k}^{-1} \mathrm{~h}^{-1}\right)\end{array}$ & $\begin{array}{l}2 \mathrm{mg} / 6 \mathrm{~h} \\
\left(9 \mu \mathrm{g} \mathrm{kg}^{-1} \mathrm{~h}^{-1}\right)\end{array}$ & $\begin{array}{l}2 \mathrm{mg} / 8 \mathrm{~h} \\
\left(7 \mu \mathrm{g} \mathrm{kg}^{-1} \mathrm{~h}^{-1}\right)\end{array}$ & $\begin{array}{l}2 \mathrm{mg} / 12 \mathrm{~h} \\
\left(4.5 \mu \mathrm{kg}^{-1} \mathrm{~h}^{-1}\right)\end{array}$ \\
\hline PT & $\begin{array}{l}\text { Not done as baseline levels available } \\
\text { from preoperative testing (Table } 1 \text { ) }\end{array}$ & $9.4 \mathrm{~s}$ & $9.1 \mathrm{~s}$ & $10 \mathrm{~s}$ & $9.4-9.9 \mathrm{~s}$ \\
\hline FVII activity & $\begin{array}{l}\text { Not done as baseline levels available } \\
\text { from preoperative testing (Table } 1 \text { ) }\end{array}$ & $361 \%$ & $361 \%$ & $291 \%$ & $285-311 \%$ \\
\hline $\begin{array}{l}\text { Outcomes and } \\
\text { interventions }\end{array}$ & Start CI-rFVIIa & $\begin{array}{l}\text { Continue CI-rFVIIa; } \\
\text { no bleeding }\end{array}$ & $\begin{array}{l}\text { Decrease CI-rFVIIa; } \\
\text { no bleeding }\end{array}$ & $\begin{array}{l}\text { Decrease CI-rFVIIa; } \\
\text { no bleeding }\end{array}$ & $\begin{array}{l}\text { Continue CI-rFVIIa; } \\
\text { no bleeding }\end{array}$ \\
\hline
\end{tabular}

PT, prothrombin time; CI, continuous infusion; rFVIIa, recombinant factor VIIa. 
continuous infusion rFVIIa was superior to bolus rVIIa regimens in terms of better maintenance of steady coagulation parameters and cost-effectiveness. Low-dose continuous infusion rFVIIa may be the optimal way to manage surgical procedures, especially major procedures in patients with severe FVIID.

\section{Author contribution}

MR was responsible for the overall conduct of this study; MR, KS, HC, SS mutually decided the regimen for use during surgery; SS performed the surgery; MF helped coordinate the study; MC managed the actual perioperative regimen; All authors contributed to manuscript writing, editing and reviewed the final submission.

\section{Disclosures}

M Rajpurkar has received honoraria from Novo Nordisk for consultation. MJ Frey is a speaker for Bayer and Nursing Advisory Board for Novo Nordisk, Baxter, Biogen Idec and Kedrion. M Callagahan, K Set, H Chugani, S Sood stated that they had no interests which might be perceived as posing a conflict or bias.

\section{References}

1 Di Minno MN, Dolce A, Mariani G. Bleeding symptoms at disease presentation and prediction of ensuing bleeding in inherited FVII deficiency. Thromb Haemost 2013; 109: 1051-9.

2 Tran HT, Tjonnfjord GE, Paus A, Holme PA. rFVIIa administered by continuous infusion during surgery in patients with severe congenital FVII deficiency. Haemophilia 2011; 17: 764-70.

3 Chitlur M, Warrier I, Rajpurkar M et al. Thromboelastography in children with coagulation factor deficiencies. $\mathrm{Br} J$ Haematol 2008; 142: 250-6.
4 Mariani G, Napolitano M, Dolce A et al. Replacement therapy for bleeding episodes in factor VII deficiency. A prospective evaluation. Thromb Haemost 2013; 109: 238-47.

5 Mariani G, Dolce A, Batorova A et al. Recombinant, activated factor VII for surgery in factor VII deficiency: a prospective evaluation - the surgical STER. Br J Haematol 2011; 152: 340-6.

6 Schulman S, Tjonnfjord GE, Wallensten R, Martinowitz U, Kenet G. Continuous infusion of recombinant factor VIIa for surgery in patients with deficiency of factor VII. Thromb Haemost 2005; 94: 1177-80.

7 Kim SH, Park YS, Kwon KH, Lee JH, Kim $\mathrm{KC}$, Yoo MC. Surgery in patients with con- genital factor VII deficiency: a single center experience. Korean J Hematol 2012; 47: 281-5.

8 Girolami A, Berti de Marinis G, Vettore S, Girolami B. Congenital FVII deficiency and pulmonary embolism: a critical appraisal of all reported cases. Clin Appl Thromb Hemost 2013; 19: 55-9.

9 Brummel ZK, Rivard GE, Pouliot RL et al. Factor VIIa replacement therapy in factor VII deficiency. J Thromb Haemost 2004; 2: 1735-44.

\title{
High titre inhibitor to factor VIII in a haemophilia carrier
}

\author{
R. MARINO, * G. MALCANGI, * M. MARGAGLIONE $\uparrow$ and C. P. ETTORRE* \\ "Centro Emofilia e Trombosi Azienda Ospedaliero-Universitaria Ospedale Policlinico Consorziale - Giovanni XXIII, Bari; \\ and †Genetica Medica, Dipartimento di Medicina Clinica e Sperimentale Università di Foggia, Foggia, Italy
}

Several aspects of mild haemophilia, defined as factor VIII coagulant activity (FVIII:C) between 0.05 and $0.40 \mathrm{IU} \mathrm{mL}^{-1}$, are currently under investigation. One is inhibitor development and treatment. Patients with mild haemophilia have been recognized as a low-risk group, with an overall incidence estimated between $3 \%$ and $13 \%$. Despite the lower risk of appearance compared with severe haemophilia, inhibitor can be an important clinical challenge regarding management of bleeding and eradication. It has been demonstrated that an intensive exposure to FVIII, mainly in a surgi-

Correspondence: Renato Marino, Centro Emofilia e Trombosi, Azienda Ospedaliero-Universitaria Ospedale Policlinico Consorziale - Giovanni XXIII, Piazza Giulio Cesare 11, 70124 Bari, Italy.

Tel.: +390805592129; fax: +390805593113;

e-mail: renato.marino@policlinico.ba.it

Accepted after revision 18 February 2014

DOI: $10.1111 /$ hae.12417 cal setting, predisposes to inhibitor appearance, the risk being higher in carriers of the Arg593Cys missense mutation in the F8 gene. This mutation, for instance, modifies FVIII three-dimensional structure since cysteine is ought to form disulphide bridges [1].

In haemophilia carriers, one of the two X-chromosomes is inactivated during embryonic life [2]. Indeed FVIII levels may range widely because lyonization is not always random. Abnormalities in the initial choice of X-chromosome inactivation have been reported in haemophilia carriers with bleeding symptoms and FVIII levels far below $0.50 \mathrm{IU} \mathrm{mL}^{-1}$ [3]. Carriers with low FVIII levels can bleed resembling the clinical picture of mild haemophilia [4]. Bleeding haemophilia carriers sometimes need replacement therapy, typically in major surgical procedures where desmopressin may not ensure sufficiently prolonged high levels of FVIII. To the best of our knowledge, only one case of spontaneous inhibitor occurrence has been reported so far in a female carrier of haemophilia [5]. 